\title{
A Study of Complications following Self-administration with Medical Abortion Pills
}

\author{
Giri A, Srivastav VR, Suwal A, Sharma B \\ Department of Obstetrics and Gynecology, Nepal Medical College and Teaching Hospital, Kathmandu, Nepal
}

Received: May 05, 2015; Accepted: June 30, 2015

\begin{abstract}
Aims: The objective of this study was to find out the complications following self-administration with medical abortion pills.
Methods: A prospective descriptive study was conducted in Department of Obstetrics and Gynecology,Nepal Medical College over a period of two years from January 2013 to December 2014 among 48 women who were admitted with abortion complications and also gave history of self-administration of abortion pills.
\end{abstract}

Results: During the study period, 48 women with history of self-medication with abortion pills were admitted with various abortion complications. There were $60 \%$ of women who had consumed abortion pills within approved nine weeks gestation while $19 \%$ had consumed after nine weeks and $21 \%$ after twelve weeks. Majority $(60 \%)$ were admitted with incomplete abortion, $4 \%$ with missed abortion, $13 \%$ with continued live pregnancy, $6.5 \%$ with septic abortion and $6.5 \%$ with ectopic pregnancy. Anemia was present in $79 \%$ of patient. More than one third of the patient had severe anemia and blood transfusion was needed in $52 \%$. Surgical evacuation was required in $71 \%$ of patient; medical abortion with repeat doses of mifepristone and misoprostol was done in was done $13 \%$ and $6.5 \%$ needed laparotomy for ectopic pregnancy.

Conclusions: Though medical abortion is considered to be highly effective and safe procedure, unsupervised selfadministration of medical abortion pills was associated with serious maternal morbidities. There should be some policy to restrict over the counter sale of this medicine.

Keywords: complications; medical abortion; self-administration.

\section{INTRODUCTION}

Each year an estimated 42 million pregnancies end in induced abortion, out of which 20 million are performed under unsafe condition. Unsafe abortion is responsible for $13 \%$ of maternal deaths worldwide. ${ }^{1}$

World Health Organization (WHO) recommends medical abortion using $200 \mathrm{mg}$ of oral mifepristone followed by $800 \mathrm{mcg}$ of misoprostol vaginally, buccally or sublingually 24-48 hours later for termination of pregnancy up to nine weeks. WHO guidelines necessitate women requesting medical abortion to confirm pregnancy, estimate correct gestational age, and locate site of pregnancy, rule out contraindications and it also recommends that the person or facility providing MA should have back up facility in case of failed or incomplete abortion. ${ }^{2}$

Medical abortion was approved in Nepal since 2009 with good success rate. As of September 2012,

\section{CORRESPONDENCE}

Dr Amrita Giri

Department of Obstetrics and Gynecology,

Nepal Medical College and Teaching Hospital, Kathmandu,

Email: amritatuladhar@yahoo.com

Phone: +977-9841222129 medical abortion was scaled up in all public hospitals, selected private hospitals and some non governmental organizations throughout the 75 districts of the country to make it easily accessible to all women. ${ }^{3}$ Despite the advances in MA services in Nepal, some women still resort to pharmacies for over the counter procurement of drugs to induce abortion. Due to unrestricted availability of these drugs, women consider this to be extremely safe option and are unaware of life threatening complications like excessive hemorrhage, sepsis or undiagnosed ectopic pregnancy that are not uncommon with its unsupervised use. This study was carried out to find the consequences of self-administration of medical abortion pill by women to induce abortion.

\section{METHODS}

This study was done in the Department of Obstetrics \& Gynecology, Nepal Medical College over a period of two years from January 2013 to December 2014 after due permission from hospital ethical committee. All the women admitted to gynecology ward with diagnosis of any abortion and early pregnancy complications were interviewed. Among them, those 
women who gave history of self-administration of medicines to induce abortion and admitted for further management of complications were identified and enrolled for the study after an informed consent. Self-administration means that these women did not visit any registered and trained medical practitioner or any health facility recognized to give medical abortion pill for consultation. Woman or her close relatives purchased MA drugs from the pharmacy over the counter without prescription. They were followed till discharge and the treatment they received were reviewed. All the relevant data were entered into specially designed proforma and the data was analysed. The data collected included age of the women, parity, gestational age at which abortion pill was taken, reason for admission to hospital, treatment received, need for blood transfusion, intensive care unit (ICU) admission and duration of hospital stay. Severity of anemia was defined according to Indian Council of Medical Research (ICMR) classification. Blood transfusion was given when hemoglobin level was less than $8 \mathrm{gm} \%$.

\section{RESULTS}

During the study period of two years, 48 women who gave history of self-administration of medical abortion pills were admitted to our hospital with various complications. The demographic profile of these women are shown in Table 1.

\begin{tabular}{|lcc|}
\hline Table 1 . Age and parity of women $(\mathrm{n}=\mathbf{4 8})$. \\
\hline Age of women & Number & $\%$ \\
$\leq 19$ years & 2 & 4 \\
$20-29$ years & 25 & 52 \\
$30-39$ years & 21 & 44 \\
Parity of women & & \\
Primigravida & 10 & 21 \\
Multigravida & 38 & 79 \\
\hline
\end{tabular}

The abortion pills were used by women of all ages, youngest one being sixteen years of age. In this study, $79 \%$ of women were multigravida and $21 \%$ were primigravida.

The gestational age at which abortion pill was consumed is shown in Table 2. In this study, we found that $40 \%$ had done medical abortion at gestational age of more than nine weeks.

\begin{tabular}{|lll|}
\hline $\begin{array}{l}\text { Table 2. Gestational age at consumption of medical } \\
\text { abortion pills }(\mathrm{n}=48) .\end{array}$ & Number & Percentage \\
\hline $\begin{array}{l}\text { Gestational age } \\
\text { at which MA } \\
\text { pills consumed }\end{array}$ & & \\
$<9$ weeks & 29 & 60 \\
9-12 weeks & 9 & 19 \\
$>12$ weeks & 10 & 21 \\
\hline
\end{tabular}

All of these women had confirmed their pregnancy by doing urine pregnancy test either at home or at the pharmacy. Gestational age was confirmed only by calculating months from last menstrual period and clinical bimanual examination and/or USG were not done. Among these women, only $8 \%$ could recall the name of the drug they had consumed and rest $92 \%$ did not know the name of the medicines. There were $42(87.5 \%)$ women who agreed on consuming five pills in total but the way they had taken the pills were different. The amount of money paid for MA pills ranged from NRs 700 to 3000 .

\begin{tabular}{|c|c|c|}
\hline Regimen of MA drug & Number & $\%$ \\
\hline $\begin{array}{l}1^{\text {st }} \text { day one tablet orally } 24 \text { hours later } \\
2 \text { tablets orally } 36 \text { hours later another } \\
2 \text { tablets orally }\end{array}$ & 14 & 29 \\
\hline $\begin{array}{l}1^{\text {st }} \text { day one tablet orally } 24 \text { hours later } \\
4 \text { tablets orally }\end{array}$ & 16 & 33 \\
\hline $\begin{array}{l}1^{\text {st }} \text { day one tablet orally } 12 \text { hours later } 4 \\
\text { tablets orally }\end{array}$ & 4 & 8 \\
\hline $\begin{array}{l}1^{\text {st }} \text { day one tablet orally } 48 \\
\text { hours later } \\
4 \text { tablets buccally }\end{array}$ & 3 & 7 \\
\hline $\begin{array}{l}1^{\text {st }} \text { day one tablet orally } \\
24 \text { hours later } 2 \text { tablets orally } \\
48 \text { hours later another } 2 \text { tablets } \\
\text { orally }\end{array}$ & 5 & 11 \\
\hline Only one tablet orally & 2 & 4 \\
\hline $\begin{array}{l}\text { Only four } \\
\text { tablets orally }\end{array}$ & 4 & 8 \\
\hline
\end{tabular}

Table 3 shows the way they have consumed the abortion pill. This table shows that only three women had taken the pills in the standard way as stated in medical abortion guideline of Nepal. They were not given any emergency contact number and did not know where to go to in case of emergency.

Twenty-nine $(60 \%)$ patients presented with vaginal bleeding on and off and were diagnosed as incomplete abortion where as two patients had to be resuscitated for hemorrhagic shock (Table 4). 


\begin{tabular}{|llr|}
\hline Table 4. Diagnosis at admission $(\mathrm{n}=\mathbf{4 8})$. & \\
\hline Diagnosis at admission & Number & $\mathbf{\%}$ \\
Incomplete abortion & $\begin{array}{l}29 \text { (2 with hemorrhagic } \\
\text { shock) }\end{array}$ & 60 \\
Complete abortion & 5 & 10 \\
Missed abortion & 2 & 4 \\
Continued live pregnancy & 6 & 13 \\
Septic abortion & 3 & 6.5 \\
Ectopic pregnancy & 3 & 6.5 \\
Total & 48 & \\
\hline
\end{tabular}

There were $5(10 \%)$ patients diagnosed as complete abortion with anemia, 2 (4\%) as missed abortion, and $6(13 \%)$ as continued viable pregnancy. All six patients with continued live pregnancy had taken the abortion pills after nine weeks of gestation. One patient with continued live pregnancy was diagnosed as late as twenty weeks.

There were $3(6.5 \%)$ patients who presented with high-grade fever, abdominal pain and vaginal bleeding and were diagnosed as septic incomplete abortion. One patient with septic abortion was in septic shock and was managed in ICU. There were 3 (6.5\%) patients diagnosed as ectopic pregnancy with two presenting with hemoperitoneum in shock and one as unruptured ectopic pregnancy and all of them underwent laparotomy.

Among these 48 women, 38 (79\%) had varying severity of anemia, which was managed with blood transfusion in 25 women.

\begin{tabular}{|lcl|}
\hline $\begin{array}{l}\text { Table 5. Severity of anemia and } \\
\text { transfusion }(\mathrm{n}=48) \text {. }\end{array}$ & Number & $\%$ \\
\hline Severity of anemia* & 6 & 12.5 \\
Very severe anemia $\mathrm{Hb}<4 \mathrm{gm} \%$ & 12 & 25 \\
Severe anemia $\mathrm{Hb} 4-6.9 \mathrm{gm} \%$ & 14 & 30 \\
Moderate anemia $\mathrm{Hb} 7-9.9 \mathrm{gm} \%$ & 6 & 12.5 \\
Mild anemia $\mathrm{Hb} 10-10.9 \mathrm{gm} \%$ & 10 & 20 \\
No anemia $\mathrm{Hb}>11 \mathrm{gm} \%$ & & \\
Blood transfusion & 14 & \\
Two units & 5 & \\
Four units & 3 \\
Five units & 3 & \\
Six units & & \\
\hline
\end{tabular}

*ICMR classification

Table 5 shows the severity of anemia and the need for blood transfusion in these women. It was very alarming to see that $12.5 \%$ of women presented with very severe anemia which can sometimes be a life threatening complication. All patients presenting with very severe anemia had done medical abortion after 12 weeks of gestation. There were 11 (23\%) patients who needed four or more units of blood transfusion.

The management of the patients done at our hospital is shown in Table 6. All the women who had failed abortion with live pregnancy opted for termination of pregnancy. All these six women had complete abortion at our center with repeat administration of mifepristone and misoprostol. Suction evacuation was done in 34 (71\%) women in this study i.e. 29 for incomplete abortion, 2 for missed abortion and 3 for septic incomplete abortion. Laparotomy was done in all three patients presenting with ectopic pregnancy. Three patients needed admission to ICU. One patient with septic abortion in septic shock and two others with very severe anemia were managed in ICU.

\begin{tabular}{|c|c|c|c|}
\hline Diagnosis & Number & Management & Number \\
\hline $\begin{array}{l}\text { Incomplete } \\
\text { abortion }\end{array}$ & 29 & $\begin{array}{l}\text { Suction } \\
\text { evacuation } \\
(\mathrm{S} \& \mathrm{E})\end{array}$ & 29 \\
\hline $\begin{array}{l}\text { Missed } \\
\text { abortion }\end{array}$ & 2 & $\begin{array}{l}\text { Suction } \\
\text { evacuation }\end{array}$ & 2 \\
\hline $\begin{array}{l}\text { Continued live } \\
\text { pregnancy }\end{array}$ & 6 & Medical abortion & 6 \\
\hline $\begin{array}{l}\text { Complete } \\
\text { abortion } \\
\text { with anemia }\end{array}$ & 5 & $\begin{array}{l}\text { Correction of } \\
\text { anemia }\end{array}$ & 5 \\
\hline $\begin{array}{l}\text { Septic } \\
\text { abortion }\end{array}$ & 2 & $\begin{array}{l}\text { I/V antibiotic } \\
\text { \& suction } \\
\text { evacuation }\end{array}$ & 2 \\
\hline $\begin{array}{l}\text { Septic } \\
\text { abortion in } \\
\text { septic shock }\end{array}$ & 1 & $\begin{array}{l}\text { I/V antibiotic, } \\
\text { Inotropes, } S \& E\end{array}$ & 1 \\
\hline $\begin{array}{l}\text { Ectopic } \\
\text { pregnancy }\end{array}$ & 3 & Laparotomy & 3 \\
\hline
\end{tabular}

\section{DISCUSSION}

WHO defines unsafe abortion as a procedure for terminating an unintended pregnancy either by individuals without the necessary skills or in an environment that does not conform to minimum medical standard or both. ${ }^{4}$ Unsafe abortion particularly invasive method can lead to severe maternal morbidity and mortality due to complications like sepsis and uterine perforation. ${ }^{5}$ To decrease the incidence of unsafe abortion and thereby reduce maternal mortality ratio of country, Nepal legalized abortion in year 2002. Despite significant progress in comprehensive abortion care services in 
the country, many Nepalese women continue to rely upon illegal and unskilled providers for abortion. A recent national study found that approximately $7 \%$ of maternal mortality were due to abortion between April 2008 and April 2009. ${ }^{6}$

WHO in the year 2003 stated that medical methods of abortion were effective and safe. Based on international evidence about its safety and efficacy and to make abortion services readily available and accessible to all women especially to poor rural women of Nepal, medical abortion using mifepristone and misoprostol was approved in Nepal since 2009. Medical abortion is even being provided at primary health center and health post of Nepal by midlevel health care providers with high success rate of $98 \%$ and low complications rate of $0.3 \%$ irrespective of doctors. ${ }^{7}$

Over the counter sale of MA tablets by pharmacies is not permitted in Nepal. Despite advances in facility and restrictions in sale of drugs, women still visit pharmacies to procure drugs for medical abortion as both registered and unregistered brands of abortion pills are easily available at pharmacy shops. The 2011 Nepal Demographic and Health Survey showed that among the women who had an abortion in the five years preceding the survey, 19\% had used tablets for their last abortion. Moreover, 5\% of them had obtained the tablets from a pharmacists or medicine shops. $^{8}$

In our study, $83 \%$ women were multiparous which was similar to the study by Mishra et $\mathrm{al}^{9}$ also reported that $78 \%$ of women who had self administered abortion pills were multiparous. This shows that women rely on medical abortion and consider it as a better method to space the birth rather than using contraception and preventing unwanted pregnancy in the first place.

Though the recommendation on medical abortion in Nepal has been restricted to early first trimester i.e. up to nine weeks or sixty three days from last menstrual period, $19 \%$ of the patient in our study used the pills between 9-12 weeks of gestation and another 21\% used it after 12 weeks which was quite alarming. In their study, Nivedita et $\mathrm{al}^{10}$ reported that $10 \%$ of patients had consumed abortion pills after nine weeks and $17.5 \%$ after twelve weeks which was similar to our study. Studies indicate that the complications of second trimester medical abortion when compared with first trimester medical abortion are high with an increased risk of bleeding, sepsis and surgical evacuation. ${ }^{11}$ Here also complications were seen more in women who had attempted second trimester abortion. All six women presenting with very severe anemia were of this group. Half of the patient with continued live pregnancy had attempted abortion after twelve weeks and two out of three cases of septic abortion were of this group showing high complication rate. Thus it is very important to confirm the gestational age before prescribing the medical abortion pill which was not done here. Even the women perceived medical abortion to be extremely safe option of termination of pregnancy even in hands of untrained personnel and at any gestational age.

In our study, $60 \%$ of the patients had incomplete abortion, 13\% had continued live pregnancy, 6.5\% presented with septic incomplete abortion and $6.5 \%$ had ectopic pregnancy. Similar to our study, Nivedita et $\mathrm{al}^{10}$ reported that the rate of incomplete abortion was $62.5 \%$, septic incomplete abortion $7.5 \%$ and failed abortion $22.5 \%$ with $80 \%$ of these patient requiring surgical evacuation. In another study conducted by Thaker et $\mathrm{al}^{12} 70.2 \%$ patient had incomplete abortion and $10.8 \%$ had failed abortion. In the study conducted by Bennett et al, ${ }^{13}$ medical abortion using correct regimen of mifepristone and misoprostol was associated with high success rate of $96.5 \%$, incomplete abortion as $1.2 \%$, failed abortion as $1.45 \%$ and missed ectopic pregnancy as $0.08 \%$.

The high rate of incomplete abortion and failed abortion in this study could be because the medical abortion regimen used by the pharmacist was not the ideal one recommended by WHO or government of Nepal. Moreover all six patients with failed abortion had consumed medical abortion pill after nine weeks of gestation.

The incidence of ectopic pregnancy was $6.5 \%$ in our study and similar to that reported as $5.4 \%$ by Thaker et al. ${ }^{12} \mathrm{~A}$ recent review of the published literature about medical abortion found that ectopic pregnancy went undetected in only 10 of every 44,789 women $(0.02 \%)$ undergoing medical abortion if all guidelines were followed. ${ }^{14}$ As these women were not counseled properly regarding the possibility of extra uterine pregnancy and bimanual examination also was not 
done to confirm gestational age and assess the uterine size, ectopic pregnancy went undetected. Moreover, ultrasonography was also not done in any patient if they did not expel product of conception.

In this study, because of unsupervised use of abortion pill and its erratic drug schedule, many women had excessive and prolonged vaginal bleeding leading to anemia. There were $6 \%$ women with very severe anemia and $12 \%$ with severe anemia in this study. Similarly Thaker et $\mathrm{al}^{12}$ reported the incidence of severe anemia in their study as $13.5 \%$. It is very alarming to see $6 \%$ of patients being admitted with very severe anemia (Hemoglobin $<4$ gm $\%$ ), as this could be life-threatening complication sometimes. Blood transfusions were needed in 23 (52\%) of patients in our study where 11 patients required four or more unit of blood transfusions. The rate of blood transfusion is higher than that reported as $23 \%$ by Ojha et al. ${ }^{15}$

In this study, there were $3(6.5 \%)$ cases of septic abortion with one patient in septic shock. Similarly Ojha et $\mathrm{al}^{15}$ reported the incidence of infection after self administration of MA as 3.5\%. In another study conducted by Bajwa et al, ${ }^{16}$ the incidence of sepsis was $6.54 \%$ following medical abortion which was similar to our study. In a systematic review covering 46,421 women, the frequency of infection after medical abortion done in ideal condition was less than $1 \% .{ }^{17}$ The higher incidence of infection here could be because these women presented to hospital late, mostly after 14 days of termination of pregnancy and all of them had attempted medical abortion after 12 weeks.

\section{CONCLUSIONS}

Medical abortion is effective and safe when carried out under medical supervision. Unsupervised use of medical abortion pills were associated with many complications like higher chances of incomplete abortion, failed abortion, hemorrhage leading to anemia and needing blood transfusion, septic abortion and missed ectopic pregnancy. So over the counter sale of medical abortion pill should be restricted. Moreover the need to educate women regarding the use of these drugs should be emphasized.

\section{DISCLOSURE}

The authors report no conflicst of interest in this work. No violation of Human rights and safety.

Funding - Nil

\section{REFERENCES}

1. Ahman E, Shah IH. New estimates and trends regarding unsafe abortion mortality. Int J Gynaecol Obstet. 2011;115(2):121-6.

2. WHO. Safe abortion: technical and policy guidelines for health systems. $2^{\text {nd }}$ edition 2012. Available from http://www who.int/reproductivehealth/publications/unsafe abortion/ 9789241548434/en/-31k

3. Tamang A, Puri M, Lama K, Shrestha P. Pharmacy workers in Nepal can provide correct information about using mifepristone and misoprostol to women seeking medication to induce abortion. Reprod Health Matters. 2014(Suppl);43:1-12

4. WHO. The prevention and management of unsafe abortion Report of a technical working group1992. Available from http://whqlibdoc.who.int/hq/1992/ WHO MSM 92.5.pdf.

5. Berer M. Why medical abortion is important for women. Reprod Health Matters. 2005; 13(26):6-10.

6. Suvedi BK, Pradhan A, Barnett S, Puri M, Rai Chitrakar S, Poudel P, et al. Nepal maternal mortality and morbidity study 2008/2009: summary of preliminary findings. Kathmandu, Nepal: Ministry of Health and Population, Department of Health Services, Family Health Division; 2009.

7. KC NP, Basnett I, Sharma SK, Bhusal CL, Parajuli RR, Andersen KL. Increasing access to safe abortion services through auxiliary nurse midwives trained as skilled birth attendants. KUMJ. 2011;36(4):260-6.

8. Nepal Demographic Health Survey (NDHS). Kathmandu: MOHP/FHD; 2011
9. Mishra N. Unprecedented use of medical abortion can be injurious to health. JEMS. 2013;2(8):856-9.

10. Nivedita K, Fatima $\mathrm{S}$. Is it safe to provide abortion pills over the counter? A study on outcome following self medication with abortion pills. J Clin Diagn Res. 2015;9(1):1-4.

11. Maarit J, Maarit N, Satu S, Elina H, Mika G, Oskari H Immediate adverse events after second trimester medical termination of pregnancy. Hum Reprod. 2011;26(4):927-32.

12. Thaker RV, Deliwala KJ, Shah PT. Self-medication of abortion pill: women`s health in Jeopardy. NHLJMS. 2014;3:26-31.

13. Bennett IM, Baylson M, Kalkstein K, Gillespie G, Bellamy SL, Fleischman J. Early abortion in family medicine: clinical outcomes. Ann Fam Med. 2009;7(6):527-33.

14. Shannon C, Brothers LP, Philip NM, Winikoff B. Ectopic pregnancy and medical abortion. Obstet Gynecol 2004; $104: 161-7$

15. Ojha N, Bista KD. Situation analysis of patients attending TU Teaching Hospital after medical abortion with problems and complications. JNMA. 2013;52(191):466-70

16. Bajwa SK, Bajwa SS, Ghai GK, Singh N, Singh A, Goraya SPS. Medical abortion: is it a blessing or curse for the developing nations? SLJOG. 2011;33:84-90.

17. Shannon C, Brothers LP, Philip NM, Winikoff B Infection after medical abortion: a review of the literature. Contraception. 2004;70(3):183-90. 